\title{
NETWORK MANAGEMENT OF \\ MACHINE-READABLE DATA FILE RECORDS
}

\author{
BY \\ Marilyn Nasatir \\ Dublin, Ohio
}

Users of machine-readable data files (MRDF) bear the responsibility to share information about data files as well as to share access to data files. Anyone needing a particular data file would find it useful to be able to sit down at a terminal and call up a record of that file by author or title or a variety of control numbers, find out where that data file is and at the same time find out how to access the file, wherever it happens to be. This presumes that someone has entered that record into the database in order to be able to retrieve it.

The bibliographic networks such as OCLC (Online Computer Library Center), RLIN (Research Libraries Information 'Network), WLN (Washington Library Network), UTLAS (University of Toronto Library Automated Systems) and NOTIS (Northwestern Online Total Information System) provide a mechanism for participants to share information resources while the networks take care of storing, maintaining and managing machinereadable records of them. At present, these records are bibliographic descriptions of books, serials, audiovisual media, maps, manuscripts, music scores, and sound recordings, making each item not only uniquely identifiable but also locatable for loan or purchase by means of institutional holdings symbols. At least one bibliographic network--OCLC--will be incorporating records of MRDF into its bibliographic database to facilitate utilization of machine-readable data.

The two primary considerations in this important system enhancement are 1) the applicability of existing standards for describing and accessing MRDF records and 2) the feasibility of integrating MRDF records with records of the traditional information sources which comprise a bibliographic network database.

\section{STANDAR.DS FOR DESCRIBING AND ACCESSING MRDF}

The need for standards to enable libraries, archives, and other information based agencies to cooperate in the description and access of machine-readable data files already being collected by academic and other institutions was demonstrated over a decade ago when the Descriptive Cataloging Committee of ALA's Cataloging and Classification Section established the Subcommittee on Rules for MRDF. Over a period of years the Subcommittee drafted position papers making recommendations on cataloging MRDF which became the basis of chapter nine ("Machine-Readable Data Files") of the second edition of Anglo-American Cataloging Rules (AACR2). ' AACR2 attempts to integrate cataloging of MRDF with all other types of materials.

The Subcommittee's recommendations supplemented by recommendations made by the Joint Steering Committee of AACR2 were followed in 1978 by the National Conference on Cataloging and Information Services for MRDF, organized to develop standards for 
bibliographic control of MRDF. Two of the recommendations of the Conference were 1) the design of a MARC (Machine-Readable Cataloging) format for MRDF and 2) the definition of products and services to be derived from cataloging MRDF. ${ }^{2}$

In response to the first Conference recommendation, the Network Development office of the Library of Congress (LC) produced Machine-Readable Data Files: A MARC Format (MRDF/MARC). ${ }^{3}$ The US/MARC Formats are standards for representing bibliographic and authority information in machine-readable form. An individual MARC format is a set of conventions for encoding a particular type of machine-readable record. The structure of a US/MARC record is determined by the American National Standard for Information Interchange on Magnetic Tape (ANSI Z39. $\overline{2}-1979$ ) and by Documentation - Format for Bibliographic Information Interchange on Magnetic Tape (IS0 2709-1973). The content of certain data elements in a MARC record is specified by the US/MARC Formats, while the content of traditional catalog elements is defined by other guidelines such as AACR2. ${ }^{4}$

In response to the second recommendation, the Inter-University Consortium for Political and Social Research (ICPSR) at the University of Michigan has created an automated cataloging system for MRDF from which such products as the guide to ICPSR'S resources, facsimilies of catalog cards, bibliographic citations, indexes, and authority lists of authors and titles will be derived. 5 The system is still in the development stage and is not yet available to the public.

Other agencies have also derived products and services from cataloging MRDF. At the federal level, standards were developed for bibliographic citations and abstracts in the production of directories of MRDF. Two examples of applications of these standards are the Directory of Data Files issued by the Bureau of the Census and American National Standard for Computer Program Abstracts (ANS1 $\times 3.88-1981$ ).

The existence of stanards thus demonstrated, the question of applicability must be addressed. In the intervening years since the adoption of AACR2, microcomputer and video game software have emerged which were not considered either in AACR2 or in MRDF/MARC. It seems more appropriate to extend the definition of MRDF to include microcomputer software than to violate input standards of the bibliographic networks by forcing these materials indiscriminately (and unretrievably) into the network formats for books or audiovisual media which were not constructed to handle them. Therefore, since input standards are rule-driven, catalogers and policy makers have been meeting to propose solutions to the problem of rules for physical description of microcomputer software. A special cataloging task force has been formed with the charge to develop a statement regarding microcomputer software description, to be published in LC's Cataloging Service Bulletin and to constitute national policy until AACR2 can be revised. This policy will be reflected in modifications to MRDF/MARC.

For assistance in the description of MRDF, catalogers and data librarians will have at their disposal Sue Dodd's new Cataloging Machine-Readable Data Files: An Interpretive Manual ${ }^{6}$ as well as a manual of microcomputer software cataloging examples which is expected to be published by the Minnesota AACR2 Training Series. 
The feasibility of integrating MRDF records into the database of a bibliographic network, which in netowrk terminology is called implementing a MRDF format, is dependent upon 1) the existence of data elements in a bibliographic record which are appropriate to MRDF users, 2) network systems and services already in place which meet the needs of MRDF users, 3) products which can be generated from these systems and services, and 4) a viable mechanism for extending treatment of traditional information sources to new formats.

\section{Data Elements}

Data elements present in a network bibliographic record needed by MRDF users are as follows: a data file description showing existence and source of data; a detailed abstract which includes the genesis and history of the file so as to link modified files: a keyword structure; links between data files and the software created to manage or operate them, including the presence and bibliographic citation of accompanying documentation, software compatibility, and linkage with other files or programs; and the applicability of the data to solving specific problems or analytic needs.

Dodd has grouped these data elements for MRDF into six categories, or levels. Level 1, Bibliographic Identity, includes such bibliographic elements as author, title, edition, distributor, notes, etc. Level 2, Data Abstract, is a descriptive summary, abstract, or subject analysis of the contents of the file. Level 3 , Classification, provides the classification codes, indexing, or descriptors. Level 4, Technical In Formation for Access, spells out the physical characteristics needed to access the MRDF such as recording density or software compatibility. Level 5 , Analysis or Use, gives a citation of documentation and related reports as well as such data collection information as how/when the data were collected, the unit of analysis, and sampling procedures. Finally, Level 6, Archiving or Maintaining, indicates records on processing, storage, use, and modifications to the MRDF. ${ }^{\prime}$ While this may sound like more information than could be incorporated into a single record, a bibliographic record currently provided by OCLC, and presumably by the other networks, can accommodate over 4000 characters, considerably in excess of the approximately 2500 required, aicording to Dodd, for an expanded bibliographic MRDF record.

\section{Systems and Services}

The data elements just discussed, along with numerous others, form the basis of the systems and services already offered in different combinations by the bibliographic networks for managing, with appropriate variations, records of books, serials, audiovisual media, maps, manuscripts, music scores and sound recordings. Prominent among these systems and services are online union catalogs; shared cataloging; serials control; subject retrieval; patron access; interlibrary loan (ILL); authority control, services for converting existing bibliographic and location data into machine-readable form and adding them to the online union catalog; and acquisitions, ordering, and fund accounting which currently interface with a directory of libraries, publishers and vendors, soon to interface directly with the vendors themselves, and easily extendable to producers and distributors of MRDF. This powerful combination of 
services will provide MRDF users with a systematic way of identifying and locating MRDF for in-house control as well as for acquiring and accessing MRDF from external sources.

Additional services not to be overlooked are the training programs, workshops, and materials provided both by the instructional coordinators of the bibliographic networks themselves and by the independent contracting network offices through which most institutions participate. It is interesting to note that the independent networks that contract with OCLC to provide services to their member libraries are al ready getting requests for the MRDF format from a variety of sources. Government iand research institutions are of course spurred on by the 1980 Census. Data archives are underutilized and eager to add their holdings to the OCLC database. "Silicon Valley" type organizations have a wide range of MRDF to control. Academic and public libraries, schools, and media centers, stimulated by the microcomputer craze, are lasking to use OCLC for cataloging, ILL (especially for documentation), acquisitions, and collection development in the lively area of microcomputer software, games, and instructional materials as well as MRDF. In fact, DIALOG (available through OCLC's Affiliated Online Services) is adding the INTERNATIONAL SOFTWARE DIRECTORY and the MICROCOMPUTER INDEX to its long list of databases.

\section{Products}

A MRDF record unambiguously tagged in an online union catalog can serve as an organic record from which catalog cards, accessions lists, and institution-specific archive tapes can be generated just as they are for other types of materials. The potential exists for such additional products as union lists, bibliographic citations, catalog entries, data abstracts, card or tape distribution of MRDF records, and subject access either printed ir on microform. ${ }^{8}$

Implementation of a MRDF Format

Although all of the bibliographic networks have the capability of implementing new formats in response to and support of LC policy and precedent, and despite Mary Magrega's paper describing the areas of activity which would be involved at UTLAS in implementing a MRDF format ${ }^{9}$, OCLC is the only bibliographic network which has actually made a commitment to implement a MRDF format and is already involved in the analysis phase.

Analysis is the first of five stages of an OCLC Cataloging Maintenance Project, the developmental process decided upon as the most viable mechanism for expediting the MRDF implementation for two reasons. One is staff and resource allocation. The other is that MRDF/MARC will be distributed by LC as an Update to its MARC Formats for Bibliographic Data (MFBD) on which many Cataloging Maintenance changes are osed.10 The product of the analysis phase will be functional specifications written oy a library systems analyst serving as Product Manager of a team of highly skilled catalogers, programmers, technical writers, quality control and testing staff.

The functional specifications will provide the basis for the four remaining stages of the Cataloging Maintenance process: development of software, preparation 'of user documentation, creation of scenarios for testing the changes, and finally pinstallation of online system and related offline production changes. One of the 
benefits of installing the MRDF format as a Cataloging Maintenance Project is that subsequent modifications distributed by LC through MRBD Updates will be easily accomodated.

\section{CONCLUSION}

A major goal of integrating MRDF into traditional library and information services by incorporating MRDF records into a bibliographic network is to communicate the availability of machine-readable materials and facilitate their utilization. It has been shown that existing standards for the description and access of MRDF, with minor modifications already in progress, are adequate for the bibliographic control of a wide range of machine-readable materials currently being collected. It has also been shown that data element descriptions, bibliographic network systems, services, and products, and a network mechanism for implementing new formats all are firmly established and easily applicable to MRDF ensuring the feasibility of the management of MRDF records by the bibliographic networks. What remains to be demonstrated is the MRDF users will avail themselves of this developing capability by contributing and accessing MRDF records by means of the various systems, services and products discussed. The vast numbers of inquiries already received suggest that they will. It is anticipated that this will be a cooperative venture in which the time and money spent by every user will be compensated for by benefits far outweighing the costs.

\section{REFERENCES}

1. American Library Association. Anglo-American Cataloguing Rules, 2d ed. Chicago: ALA, 1978.

2. Sue A. Dodd. "Toward Integration of Catalog Records on Social Science MachineReadable Data Files Into Existing Bibliographic Utilities: A Commentary." Library Trends 30, n.3 (Winter 1982): 342 .

3. Sue A. Dodd. Working Manual for Cataloging Machine-Readable Data Files (Chapel Hill: Social Science Data Library, Liniversity of North Carolina, 1976, mimeo).

4. "The US/MARC Formats: Underlying Principles." Library of Congress Information Bulletin (in press).

5. Carolyn Geda of ICPSR, private communication.

6. Sue A. Dodd. Cataloging Machine Readable Data Files: An Interpretive Manual.

7. Dodd, "Toward Integration," pp. 350-351.

6. Marilyn Nasatir. "Machine-Readable Data Files and Networks." Information Technology and Libraries (in press). 
9. Mary K. Magrega. "A Bibliogranhic Utility's Implementation of the MARC Format for Machine-Readable Data Files." (Toronto: University of Toronto Library Automated Systems, 1981, mimeo).

10. United States. Library of Congress. Automated Systems Office. MARC Formats for Bibliographic Data. Washington: Library of Congress, 1980.

\section{ICDBHSS $/ 83$}

\section{INTERNATIONAL CONFERENCE ON DATA BASES IN THE HUMANITIES AND SOCIAL SCIENCES}

The ICDBHSS/83 will be held in Rutgers, the State University, on the Douglas College campus, at New Brunswick, New Jersey, from June 10 to 12 . It is intended that the conference be broad in scope and that there be a true exchange of ideas and information; not only between the social sciences and the humanities, but also between the various fields in each area.

Speakers from twenty-four countries will present papers concerning data bases, their structure, accessibility, and uses in the fields of archaeology, art, artificial intelligence, criminology, education, history, law, lexicology, linguistics, literature, music, philosophy, sociology, and religion, to mention only the broader areas. Most of the fields just mentioned extend over to other fields, e.g., arthistory, socio-history, music-library, literary-linguistics.

The language of the conference will be English.

For additional information contact: Dr. Fobert Allen

Bishop House, Room 306A

Rutgers University

New Brunswick, N.J. 08903

(201) $932-7335$ or (201) $932-7505$

\section{INDEX OF PUBLIC OPINION POLL QUESTIONS COMPILED}

Dennis Gilbert at the University of Louisville is compiling the AMERICAN PUBLIC OPINION INDEX, which will provide a tooical listing of all questions asked in American public opinion polls, some information about where to get the results of the survey, and some information about the survey in which the questions were asked. The first volume will include auestions asked in 1951. The second volume will cover 1982. By joing beyond abstracts of polls to question level indexing, Gilbert hodes to provide researchers with the kind of detail they need to directly access the particular topic in which they are interested. Like any other index, APOl will not give researchers ;ubstantive information, but instead will tell where to find it. Consequently, solling agencies will retain control over their findings, especially those not yet ublished.

For further information, write to Dennis rilbert, 501 Highwood Dr., Louisville, iY 40206 or call (502) 893-2527. 